\title{
A Study of Determinants of Use of Healthcare Services in India
}

\author{
Gulrez Shah Azhar', Ali Amir², Najam Khalique³, Zulfia Khan ${ }^{4}$ \\ ${ }^{1}$ Senior Lecturer, Indian Institute of Public Health Gandhinagar, India. ${ }^{2}$ Reader, Department of Community Medicine, \\ JN Medical College, AMU Aligarh. ${ }^{3,4}$ Professor, Department of Community Medicine, JN Medical College, AMU Aligarh.
}

\section{A B STRACT}

Context: Healthcare in India is a complex mix of providers, facilities and payment systems with low budgetary support from the government. After decades of neglect there is realisation that health is a priority and spending should be increased. Also there is a shortage of evidence and subsequently a need to suggest direction based on this evidence. Aims: To determine the burden of illness in the study population; find out the types of healthcare facilities used during illness; study the medico-social and economic factors influencing utilization of healthcare services. Settings and Design: 10 locations, 5 villages and 5 urban areas in the field practice areas of department of Community Medicine, AMU Aligarh. Methods and Material: Cross sectional field based study on 2518 individuals using systematic random sampling. Participants interviewed and data collected on a piloted proforma. Data Collected in two parts, initial information about burden of illness and later information of treatment seeking behaviour. Statistical analysis used: Chi Square tests, Proportions. Results: Disease severity and economic reasons play a part in treatment seeking behaviour. Some kind of treatment is sought in majority of illnesses. Treatment seeking increases with the perceived severity of illness. Choice of treatment facilities depends on various factors including availability, cost and type of illness. Conclusions: There is a hidden need for healthcare in rural areas which is expected to increase with rising awareness about health. Poverty is the major reason for not seeking any treatment in urban areas reflecting an urgent need of health provision for poor.

Key words: Health Services, Health Systems, Utilization, Treatment seeking behaviour, India.

Key messages: Fewer illnesses are considered severe enough to warrant treatment in rural areas. The major reason in urban areas for not seeking any form of treatment is poverty. Illnesses considered severe are significantly more likely to result in visit to healthcare facility. Complimentary and alternative systems are preferred for chronic illnesses.

\section{INTRODUCTION}

Historically in India, healthcare receives particularly low spending as budgetary support (Rs. 22300 crores for health and family welfare in the union budget 2010 compared to total global expenditure for health in the range of US $\$ 4.1$ trillion) ${ }^{1,2}$ India is one of the five countries in the world where public spending is less than 0.9 per cent of GDP, ${ }^{3}$ of that a large part $(80 \%)$ is spent on wages and salaries leaving very meagre resources for drugs, supplies, equipment, infrastructure and maintenance.

\section{Address for correspondence:}

Dr. Gulrez Shah Azhar, MBBS, MD, MPH

Senior Lecturer, Indian Institute of Public Health-Gandhinagar,

Public Health Foundation of India, Sardar Patel Institute Campus

Drive in Road, Thaltej, Ahmedabad 380054.

Phone: +91 7940240444

Fax: +91 7940240445

Email: gsazhar@iiphg.org

DOI: 10.5530/ijmedph.3.2011.10
Healthcare in India is particularly complex with a mix of providers of different streams of medicine along with unlicensed practitioners commonly called jhbolachbap or quacks; a mix of facilities of public private and charitable; a mix of payment systems from out of pocket to social or commercial insurance to free care. ${ }^{4}$ There are also a number of related issues which have a bearing on healthcare they include shortage of postgraduate training opportunities, physician migration and vertical health programs. ${ }^{5-7}$

Expansion of healthcare is a priority of these times. ${ }^{8}$ From being "forgotten" when the League of Nations was drafted it has now proceeded to be considered a basic human right and a duty of the government to be able to provide it to all the citizens. The government has also committed itself to increased spending (from the current level of $<1 \%$ of GDP to 2-3\%). Approaches towards this expansion ranges from a centrally planned system to a laissez-faire approach., ${ }^{910}$ Therefore, a realistic formulation of health policies and programmes requires a better understanding of healthcare seeking behaviour. 
There are few studies on the pattern of utilization of healthcare services. ${ }^{11}$ The evidence from other countries cannot be realistically applied to India due to the vast size of the country and the complex structure of the Indian health system. This study is an attempt to understand the pattern of utilization of healthcare services during illness and various factors influencing it. It is expected that the evidenced unearthed would be helpful in finding solutions for this complex problem. The objectives of this study were

- To determine the burden of illness in the study population.

- To find out the types of healthcare facilities used during illness.

- To study the medico-social and economic factors influencing utilization of healthcare services.

\section{MATERIALS}

The study was conducted in the district of Aligarh in north India. In view of perceived differences between rural and urban areas, data was collected from the field practice areas of both rural and urban health training centres of the department of Community Medicine of J N Medical College AMU Aligarh. The data for this cross sectional study was collected in a period of one year, from August 2006 to July 2007.

The sample size was calculated using the formula $\boldsymbol{n}=\boldsymbol{z}_{1-\alpha / 2}^{2}$ $\boldsymbol{p}(1-\boldsymbol{p}) / \boldsymbol{d}^{2}$ where $\mathbf{n}$ is the sample size, $\mathbf{d}$ represents the absolute precision, $\mathrm{p}$ is anticipated prevalence, $z_{1-\alpha / 2}^{2}=$ value of standard normal deviate corresponding to $5 \%$ level of significance. The researcher used household as the sampling unit. This is the convention for sampling in similar studies and has been used by various authors. ${ }^{12-15}$

Using the above formula, total number of household to be studied comes out to be 385 . As the average family size $=6,{ }^{[16]}$ total number of individuals to be studied $=$ 2310. These houses were selected from the population using systematic random sampling. Each selected household was visited once for the interview, in case of closure or nonavailability of members, a second visit was made while in case of refusal the next household was visited for interview.

The study was conducted in two stages. To understand the behavior pattern for utilization of types of healthcare facilities the burden of illness in the study population was determined. Those who reported themselves as ill in the last 15 days were subsequently probed for the kind of health facilities and healthcare services availed and the medicosocial and economic factors which determined this choice.

The family members were interviewed on a preformed and pretested Proforma based on the objectives of the study.
The Proforma was in two parts. Part 1 included family census, information about caste, income, religion and whether there was any $\mathrm{H}$ /o illness in any member of the household. While part 2 included information about illness, utilization of healthcare services, satisfaction with healthcare services etc.

Before the start of fieldwork, ethical clearance was taken from the ethics committee of the department of Community Medicine of J N Medical College. A pilot study was done to test the Performa and the necessary modifications were made. The selected households were visited along with the medico-social workers of the Department of Community Medicine and informed verbal consent was taken from each family for the interview. Then the selected cases were interviewed on the proposed Performa. Confidentiality was maintained so that the subjects could answer more openly and truthfully. For children below age 15, parents or guardians were interviewed. For adolescents age 15-18, consent was obtained from both the parent and the child. For ascertaining whether an individual had suffered from any ailment during the reference period and whether she/ he had received any medical treatment on that account, a set of probing questions were put to the informant. The illness was classified on the basis of modified WHO lay reporting of illness. The data was entered in SPSS 17 software and analyzed for relationship between the dependent and independent variables.

\section{RESULTS}

In the present study 149 illnesses were recorded in a period of 15 days for 2518 individuals, in other words 118.3 per 1000 population or $11.8 \%$ individuals were affected by illness during a given month. Some researchers have also taken a 30 day reference period for similar studies. The researchers in this study took a 15 day reference period to minimize any possibility of recall bias. It was considered that people would be likely to

\section{Table 1: Inclusion and Exclusion Criteria for the study}

\section{Inclusion Criteria}

1 Residents of households registered with the Urban or Rural Health Training Centre.

2. Informed verbal consent was taken from family and individuals for the interview.

3. Individual reporting any illness in the last fifteen days. 4. Death due to illness in last fifteen days.

\section{Exclusion Criteria}

6. Individuals not giving consent for interview and/or examination 7. Patients whose duration of illness was less than two days. *

*This was done to exclude minor ailments and to provide scope for detailed investigation in the process of decision making and pattern of curative behavior. 
forget mild illness for which they took no treatment if a longer recall period was used.

It was observed that presence of illness was high in the $>60$ year age group $(16.9 \%)$ followed by $<5$ year age group $(9.6 \%)$. This "U" shaped pattern was seen both in rural as well as urban areas. It was observed that females had a higher presence of illness in all age groups except $<5$ years. In $<5$ year age group males had higher rates of illness both in rural and in urban areas.

Table 2 lists the perceived severity of illness according to sick person's perception, as mild moderate and severe and its rural and urban distribution. The majority of illnesses were perceived to be mild or moderate $38.3 \%$ and $40.9 \%$ respectively) and only $20.8 \%$ illnesses were considered to be severe. In rural areas illnesses were considered severe more often $29.5 \%$ than in urban areas $14.9 \%$.

Table 3 shows the percentage of sick persons availing any form of treatment. In both urban and rural areas 80.5 and $80.6 \%$ of sick persons avail any form of treatment and there is no significant rural urban variation. Overall 80.5\% of people seek any form of treatment for illnesses.

Table 4 shows the reasons why people choose not to seek medical care for their illnesses. It is seen that in rural areas the major cause is illness not considered serious (58.3\%) while in urban areas most patients did not seek medical care because of reasons of poverty (58.8\%). Other reasons mentioned were distance, paucity of time, inconvenient timings of health facilities and long waiting time.

\begin{tabular}{lrrrrrr} 
Table 2: Perceived Severity of IIIness & \multicolumn{2}{c}{ Total } \\
\hline \multirow{2}{*}{$\begin{array}{l}\text { Perceived } \\
\text { severity of }\end{array} \quad$} & \multicolumn{3}{c}{ Place of study } & \multicolumn{2}{c}{ Rural } & \multicolumn{2}{c}{ Urban } & \multirow{2}{*}{ No. } & $\%$ \\
\cline { 2 - 5 } illness & No. & $\%$. & No. & \multicolumn{1}{c}{$\%$. } & \\
\hline Mild & 21 & 33.8 & 36 & 41.4 & 57 & 38.3 \\
Moderate & 23 & 37.7 & 38 & 43.7 & 61 & 40.9 \\
Severe & 18 & 29.5 & 13 & 14.9 & 31 & 20.8 \\
Total & 62 & 100.0 & 87 & 100.0 & 149 & 100.0 \\
\hline
\end{tabular}

\begin{tabular}{|c|c|c|c|c|c|c|}
\hline \multirow{3}{*}{$\begin{array}{c}\text { Treatment } \\
\text { availed }\end{array}$} & \multicolumn{4}{|c|}{ Place of study } & \multicolumn{2}{|c|}{ Total } \\
\hline & \multicolumn{2}{|c|}{ Rural } & \multicolumn{2}{|c|}{ Urban } & \multirow[t]{2}{*}{ No. } & \multirow[t]{2}{*}{$\%$} \\
\hline & No. & $\%$ & No. & $\%$ & & \\
\hline $\begin{array}{l}\text { Treatment } \\
\text { not availed }\end{array}$ & 12 & 19.4 & 17 & 19.5 & 29 & 19.5 \\
\hline $\begin{array}{l}\text { Treatment } \\
\text { availed }\end{array}$ & 50 & 80.6 & 70 & 80.5 & 120 & 80.5 \\
\hline Total & 62 & 100.0 & 87 & 100.0 & 149 & 100.0 \\
\hline
\end{tabular}

$\chi^{2}=0.003$ D.f $=1 p>0.05$ insignificant
Table 5 shows the utilization of health services according to perceived severity of illness. As is evident from the table the utilization of health services increases with increase in the severity of illness with the majority of sick persons utilizing some form of health service for severe illness. This finding is also statistically significant.

Table 6 shows a number of people using multiple sources of treatment. The majority of people had first contact with a public/government source of treatment (44.2\%) followed by private practitioners $(30.8 \%)$ and others $(12.5 \%)$, alternative systems and home remedies only had a minor role. When second source was considered, this pattern remained the same $(44.2 \%, 41.8 \%$ and $4.6 \%)$. But when third source was considered the majority was opting for alternative systems of medicine $(40.0 \%)$.

Table 7 shows that significantly higher numbers of people in urban areas were going to government health facilities $(48.7 \%)$ as compared to rural areas where the majority was going to private health centers $(42.0 \%)$. Utilization of home care was higher in rural areas $(10.2 \%)$ while in urban areas, a large number of people took over the counter medicines $(20.3 \%)$.

\section{DISCUSSION}

An interesting finding was that illness reporting was more in the extremes of age and more women complained of

\begin{tabular}{|c|c|c|c|c|c|c|}
\hline \multirow{3}{*}{$\begin{array}{l}\text { Reasons } \\
\text { for not } \\
\text { availing } \\
\text { treatment }\end{array}$} & \multicolumn{4}{|c|}{ Place of study } & \multicolumn{2}{|c|}{ Total } \\
\hline & \multicolumn{2}{|c|}{ Rural } & \multicolumn{2}{|c|}{ Urban } & \multirow[t]{2}{*}{ No. } & \multirow[t]{2}{*}{$\%$} \\
\hline & No. & $\%$ & No. & $\%$ & & \\
\hline $\begin{array}{l}\text { Ailment not } \\
\text { considered } \\
\text { severe }\end{array}$ & 7 & 58.3 & 4 & 23.5 & 11 & 37.9 \\
\hline Poverty & 5 & 41.7 & 10 & 58.8 & 15 & 51.7 \\
\hline Others & 0 & 0 & 3 & 17.6 & 3 & 10.3 \\
\hline Total & 12 & 100.0 & 17 & 100.0 & 29 & 100.0 \\
\hline
\end{tabular}

Table 5: Treatment availed according to severity of illness

\begin{tabular}{|c|c|c|c|c|c|c|}
\hline \multirow{3}{*}{$\begin{array}{l}\text { Severity } \\
\text { of illness }\end{array}$} & \multicolumn{4}{|c|}{ Treatment taken } & \multicolumn{2}{|c|}{ Total } \\
\hline & \multicolumn{2}{|c|}{ No } & \multicolumn{2}{|c|}{ Yes } & \multirow[t]{2}{*}{ No. } & \multirow[t]{2}{*}{$\%$} \\
\hline & No. & $\%$ & No. & $\%$ & & \\
\hline Mild & 20 & 35.1 & 37 & 64.9 & 57 & 100.0 \\
\hline Moderate & 7 & 11.5 & 54 & 88.5 & 61 & 100.0 \\
\hline Severe & 2 & 6.5 & 29 & 93.5 & 31 & 100.0 \\
\hline Total & 29 & 100.0 & 120 & 100.0 & 149 & 100.0 \\
\hline
\end{tabular}


sickness across all age groups except in under fives (Table 1). A likely explanation for this $U$ shaped illness pattern could be that while households were more likely to report illness of infants than of elder children, girls were less likely to be reported ill than boys due to our social organization.

The table showing rural-urban contrasts in severity of illness (Table 2) is a representation of perception of health and sickness in the community. There is a concept of a whole spectrum of illness with absolutely normal health on one end and extreme sickness on the other end. In between are various stages of ill health. Thus the health condition might be called as illness but not severe enough to warrant medical treatment.

The reason a higher proportion of people in urban area were not able to avail health services (Table 4) may be due to the fact that the urban areas covered under this study were significantly poorer than the rural areas. This is a very important finding in the sense that it demonstrates that economic factors have a very important role in utilization of care. This is also reflected in the shift in the current international opinion of not charging user fees for provision of and access to care. ${ }^{17}$ It indicates a major shift in the conventional wisdom offered by the World Bank under its debatable "structural adjustment" policies.

The first choice for healthcare seeking has been government facility (Table 6). This is a momentous finding as it demonstrates that people opt for free care. All government

\begin{tabular}{lrrrrrr} 
Table 6: Choice of facilities & & & \\
\hline $\begin{array}{c}\text { Health facilities } \\
\text { utilized for } \\
\text { treatment }\end{array}$ & \multicolumn{2}{c}{$\begin{array}{c}\text { First } \\
\text { source }\end{array}$} & $\begin{array}{c}\text { Second } \\
\text { source }\end{array}$ & $\begin{array}{c}\text { Third } \\
\text { source }\end{array}$ \\
\cline { 2 - 7 } & No. & \multicolumn{1}{c}{$\%$} & No. & $\%$ & No. & $\%$ \\
\hline Government & 53 & 44.2 & 19 & 44.2 & 0 & 0 \\
Private & 37 & 30.8 & 18 & 41.8 & 1 & 20 \\
Alternative & 5 & 4.2 & 3 & 6.9 & 2 & 40 \\
Home & 10 & 8.3 & 1 & 2.3 & 1 & 20 \\
OTC/others & 15 & 12.5 & 2 & 4.6 & 1 & 20 \\
Total & 120 & 100 & 43 & 100 & 5 & 100 \\
\hline
\end{tabular}

\begin{tabular}{lrrrrrr} 
Table 7: Choice of facilities according to location \\
\hline \multirow{3}{*}{$\begin{array}{l}\text { Source of } \\
\text { treatment }\end{array}$} & \multicolumn{3}{c}{ Place of study } & \multicolumn{2}{c}{ Total } \\
\cline { 2 - 5 } & \multicolumn{2}{c}{ Rural } & \multicolumn{2}{c}{ Urban } & \multirow{2}{*}{ No. } & $\%$ \\
\cline { 2 - 5 } & No. & \multicolumn{1}{c}{$\%$} & No. & $\%$ & & \\
\hline Government & 19 & 38.0 & 34 & 48.7 & 53 & 44.2 \\
Private & 21 & 42.0 & 16 & 22.8 & 37 & 30.8 \\
Alternative & 3 & 6.0 & 2 & 2.8 & 5 & 4.2 \\
Home & 6 & 12.0 & 4 & 5.7 & 10 & 8.3 \\
OTC/others & 1 & 2.0 & 14 & 20.0 & 15 & 12.5 \\
Total & 50 & 100.0 & 70 & 100.0 & 120 & 100.0 \\
\hline & & & & & & \\
\end{tabular}

$\chi^{2}=13.89$ D.f $=4 p>0.05$ significant care available in the study area was free of cost or required a token payment of ' 1 for consultation while all the investigations and medicines provided in the government facility were free of cost. The community is willing to avail the service from public facilities despite inconvenient opening times. People were also of the belief that service offered in government facilities was of a high standard. Use of alternative systems as a third source may be a reflection of treatment seeking behavior for chronic health conditions where patient try out different treatment systems in hope of a permanent cure.

Table 7 shows that less people in rural areas go to government facilities than in urban areas. These findings are a reflection of availability and accessibility of services in rural and urban areas. In urban areas it is easier to visit government facilities as they are much closer to the study areas. While in rural areas the village population, in most cases, had to travel to adjoining villages or block headquarter to visit the government health facility. This also explains why the utilization of home care was more common in rural areas while over the counter medicines being easily available in chemist shops in urban areas were more commonly utilized there. In the rural setting, a belief in natural remedies and use of everyday food items for treating common illness may also play a role which reflects higher utilization of home care.

\section{Strengths and limitations}

Some of the limitations of this study include questions on its external validity. Considering the huge size of our country the findings from this study can not be assumed to represent the treatment seeking behaviour of the whole country. There may be considerable variations between different parts of the country including the presence and absence of different streams of medicine. For example no practitioner was found for Siddha system of medicine which is quite common in the southern part of the country. There is also variation among different states in terms of health and economic status of populations and even the quality of services being provided by the respective state health facilities.

Considerable rural urban differences exist in treatment seeking behaviour. These differences are related to perceptions about severity of illness. Fewer illnesses are considered severe in rural settings. The major reason for not taking any treatment in rural areas is that the illness is not considered severe enough to warrant treatment. This demonstrates a hidden need for healthcare which is expected to increase with rising awareness about health issues. Also the higher usage of private compared to public facilities in rural areas reveals the need for their greater coverage there.

Disease severity and economic reasons pay a part in treatment seeking behaviour. As expected, illnesses which 
are considered severe are significantly more likely to result in a visit to a healthcare facility compared to mild and moderate illness. The major reason in urban areas for not seeking any form of treatment is poverty. This dependence of treatment seeking behaviour on economic situation of the household demands a comprehensive social protection. Considering that expenditure on healthcare is the second most important reason for falling into poverty, any scheme of the government which assures at least a minimum level of health protection to the population is much needed.

For different types of illnesses (acute/chronic) people go to different types of facilities. The study points towards a tendency of "shopping for providers" with people going to different providers for a single illness if they are not satisfied with the treatment offered. Complimentary and alternative systems are preferred for chronic illnesses. This market driven care may lead to a departure in the way medicine is practiced under pressure from market forces. This defensive practice may have adverse outcomes including but not limited to inadequate investigations, antibiotic overuse, focus on symptomatic treatments compared to diagnosis, poaching of patients, inadequate information being given to the patient. Due to asymmetry of knowledge between the client and provider the public may not be in a position to realise the damage this may be causing in this situation to their health.

Conflict of interest notification: none

\section{REFERENCES}

1. Government of India, The Union Budget of India. 2010: New Delhi.

2. Bawaskar, H.S. and P.H. Bawaskar, Political neglect in India's health. The Lancet. 364(9430): p. 248-248.

3. Government of India, M.o.H.a.F.w., National Health Policy. 2002: New Delhi.

4. Bhat, R., The private/public mix in health care in India. Health Policy and Planning, 1993. 8(1): p. 43-56.

5. Azhar, G. and A. Jilani, Future of community medicine in India. Indian Journal of Community Medicine, 2009. 34(3): p. 266.

6. Mullan, F., Doctors for the world: Indian physician emigration. Health Affairs, 2006. 25(2): p. 380.

7. Msuya, J., Horizontal and vertical delivery of health services: what are the tradeoffs. Background paper for the World Development Report, 2004.

8. Reddy, K., et al., Towards achievement of universal health care in India by 2020: a call to action. The Lancet, 2011.

9. Bhore, J., R. Amesur, and A. Banerjee, Report of the health survey and development committee. Volume I to, 1946.

10. Berman, P., Rethinking health care systems: Private health care provision in India. World Development, 1998. 26(8): p. 1463-1479.

11. NSSO, Report Number 441, Morbidity and Treatment of Ailments. 1998: India.

12. Nair KS, Cost of heal thcare - A study of unorganized labour in Delhi. Perspectives and issues, 2001. 24(2): p. 88-98.

13. Pandit DD, P.N., Waingankar PJ. Evaluation of $\mathrm{MCH}$ services provided by an urban health center. Health and population - perspectives and issues, 1996. 19(1): p. 41-49.

14. Samuel GER, G.J., Wadhwa VS, Satisfaction and utilization of primary healthcare service facilities in Karnataka. Perspectives and issues, 1992. 15(3 and 4): p. 140-152.

15. Bhatnagar S, Health services development in urban areas. Perspectives and issues, 1989. 12: p. 71-93.

16. Government of India, Census of India. 2009. p. Census of India.

17. Yates R, Universal health care and the removal of user fees. The Lancet, 2009. 